\title{
An autosomal dominant syndrome with 'acromegaloid' features and thickened oral mucosa
}

\author{
HELEN E HUGHES*, PHYLLIS J McALPINE $\dagger$, DIANE W COX*, AND \\ SYLVIA PHILIPPS $\ddagger$
}

From ${ }^{*}$ the Departments of Paediatrics and Genetics, and the Research Institute, Hospital for Sick Children and University of Toronto, Toronto, Ontario; the Division of Human Genetics and Departments of Paediatrics and Child Health and Anatomy, and $¥$ Section of Blood Group Serology, Department of

Paediatrics and Child Health, University of Manitoba, Winnipeg, Manitoba, Canada.

SUMMARY A previously undescribed autosomal dominant syndrome has been observed in a large kindred with affected relatives spanning at least five generations. The phenotype is highly variable and appears to show complete penetrance. Affected persons have a progressively coarse, acromegaloid-like facial appearance and thickening of the lips and intraoral mucosa. The differences are discussed between this syndrome and three rather similar syndromes, pachydermoperiostosis, the Ascher syndrome, and multiple neuroma syndrome.

In this paper we describe a large kindred with a previously unreported syndrome segregating in an autosomal dominant fashion. Despite similarities in facial appearance, the syndrome appears to be distinct from acromegaly, pachydermoperiostosis, and the Ascher and multiple neuroma syndromes. There is no known associated health risk. Although some affected persons were concerned about their appearance, most were unaware of any problem until the proband requested corrective surgery. At

Received for publication 17 May 1984 Accepted for publication 12 July 1984. that time the familial nature of the disorder was revealed.

\section{Case report}

The proband (IV.15) was first seen at 17 years of age when he was admitted to hospital for facial cosmetic surgery (fig 1). His main concerns were progressively thickened lips and thickened skin around the eyes, the latter leading to narrowed palpebral fissures. Other distinctive facial features included a bulbous nose, thickened intraoral mucosa with exaggerated rugae and frenula, and a furrowed

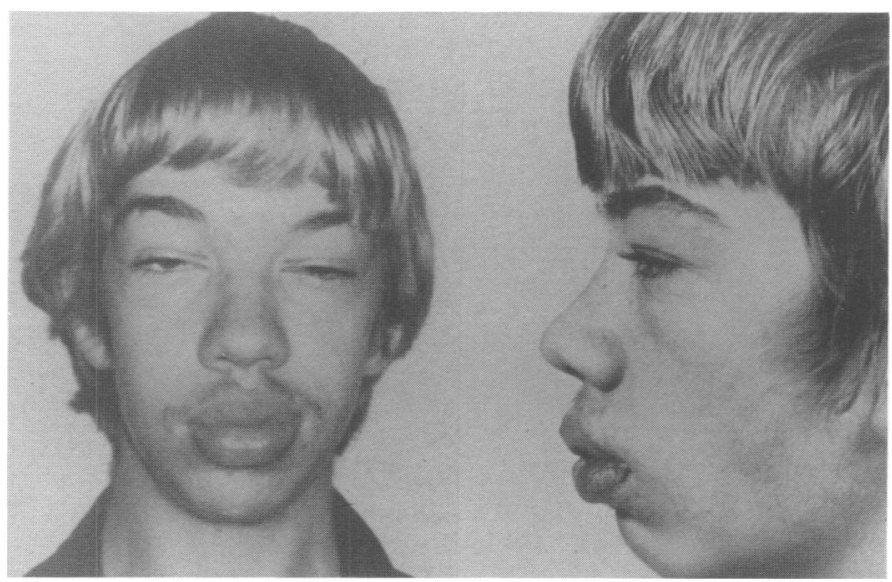

FIG 1 Proband (IV.15) at 17 years of age. Note markedly thickened lips and fullness of the upper eyelids and infraorbital areas leading to narrowed palpebral fissures. 


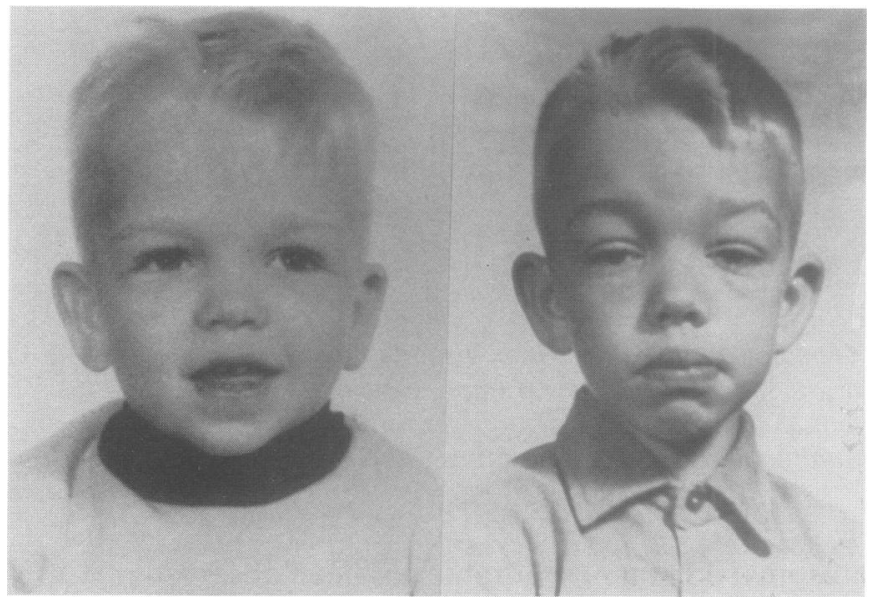

FIG 2 Progession of coarseness. Proband at 2 years (left) and 5 years (right).

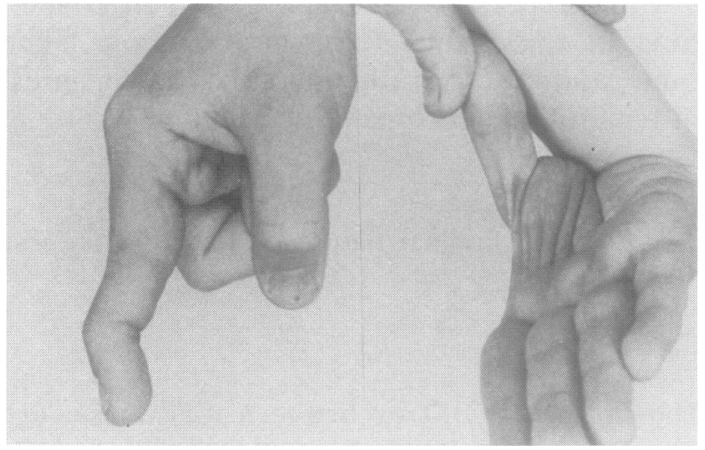

FIG 3 Proband's hand demonstrating hyperextensible metacarpophalangeal and interphalangeal joints. Note absence of clubbing. tongue. These progressive facial changes were first noted at around 3 to 4 years of age (fig 2). The hands were large with a doughy consistency to the skin and the metacarpophalangeal and interphalangeal joints were hyperextensible (fig 3 ). The skin consistency in areas other than the extremities was normal and there was no finger clubbing. The physical examination was otherwise unremarkable. The height, weight, and head circumference were within normal limits.

Following an uneventful pregnancy the proband was born at term with a birth weight of $3360 \mathrm{~g}$. His perinatal period was unremarkable and his early developmental milestones were reported to be within normal limits. However, at the age of 2 years he suffered a grand mal seizure which lasted about 3 hours. Records of the investigations carried out at

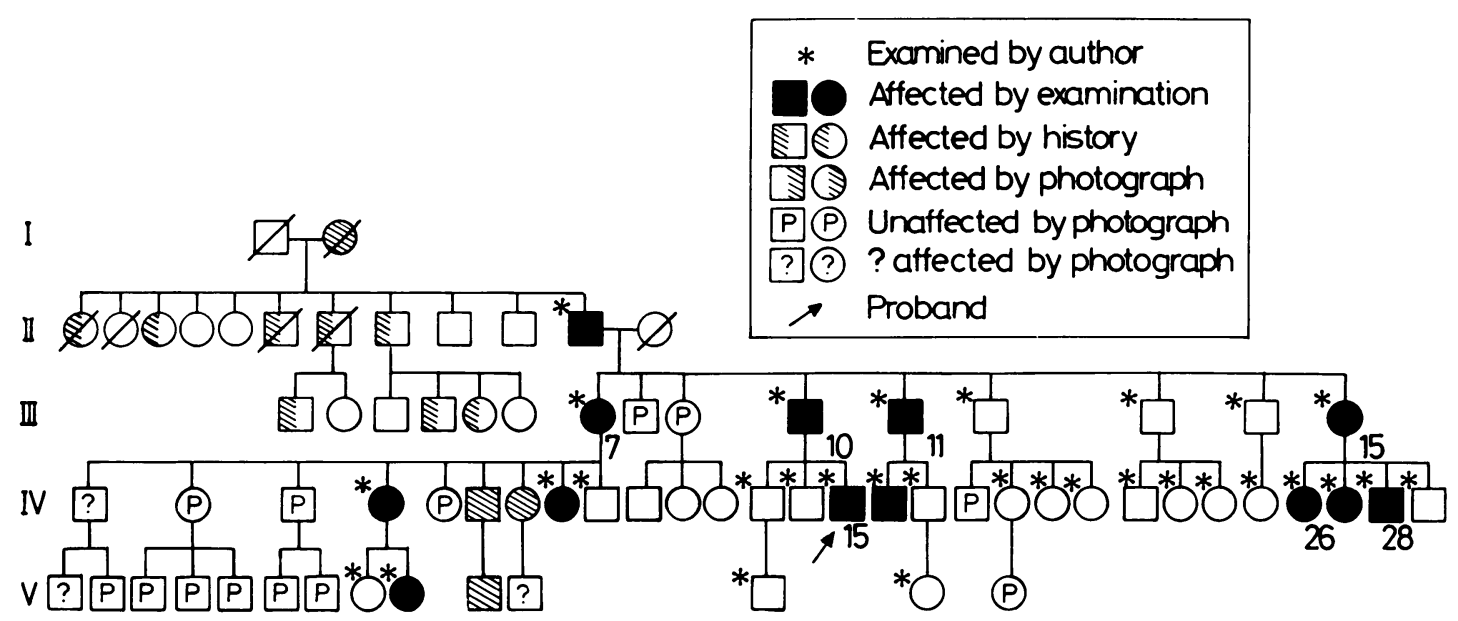

FIG 4 Family pedigree. 
that time are unavailable. He was treated with phenobarbitone for the next 10 years and had no recurrence of seizures, but he experienced learning difficulties during his school years and required special class placements. His seizures and subsequent learning difficulty are unlikely to be related to the syndrome as all other affected subjects in the family appear to be of normal intelligence.

\section{Family history}

The pedigree is shown in fig 4 . The syndrome appears to be completely penetrant, with males and females equally affected. The affected relatives ranged in age from 2 to 78 years and all were in good general health. None had evidence of an endocrine disturbance and all were of normal height and weight. None required special education suggesting that their intelligence was within normal limits. Before the development of the external phenotype, family members had been able to identify affected persons as early as 6 months of age, based on observations of the thickened intraoral mucosa. The changes in the face and extremities were highly variable and progressive as shown in photographs of the proband's cousin (fig 5). Two of the paternal aunts (figs 6 and 7) had an 'acromegaloid' appearance with coarsened facial features and thickened lips and eyelids.

The more mildly affected relatives manifested

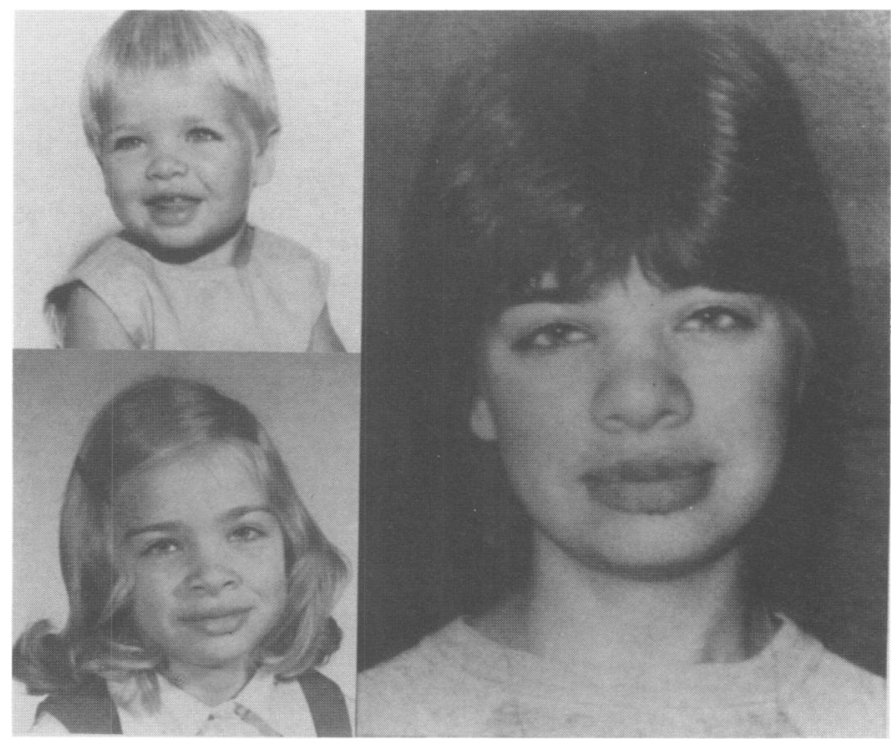

FIG 5 Proband's first cousin (IV.26) at ages 2,6 , and 16 years showing progression of facial features.

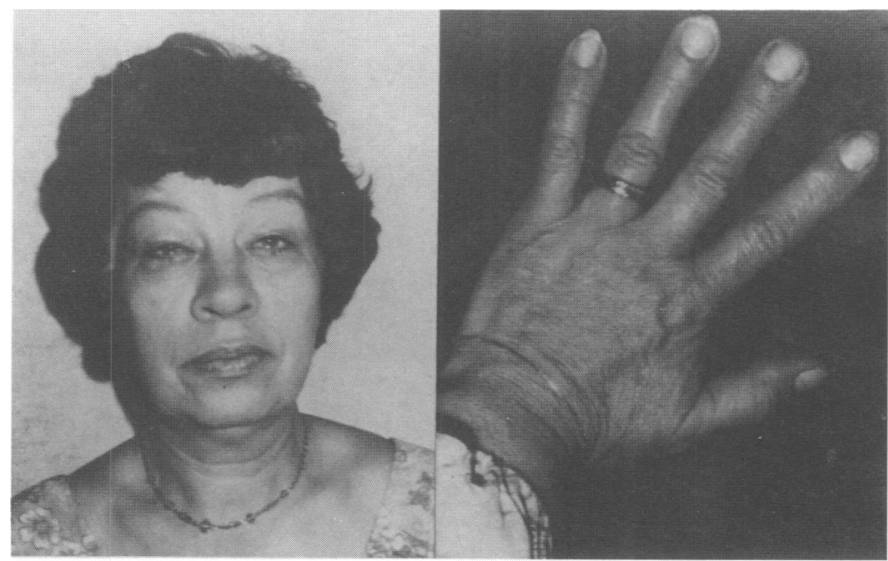

FIG 6 Paternal aunt (III.7). Note acromegaloid-like appearance and raising of eyebrows caused by thickened upper eyelid skin. The hand is broad with non-tapering digits. 




FIG 7 Paternal aunt (III.15) aged 37 years showing coarse facial features and $a$ bulbous nose.

only slight swelling of the lower lip and upper eyelids. Compared with the proband, the father had minimal lip enlargement. However, he had a bulbous nose and loose skin around the eyes (fig 8), and his intraoral mucosa was markedly thickened. His hands were broad with squared-off terminal phalanges and the skin, like that of the proband, had a doughy consistency.

\section{Investigations}

A chromosome study on the proband showed a normal 46,XY banded karyotype. Thyroid function and growth hormone assay in the proband and in three randomly selected relatives aged 56 years

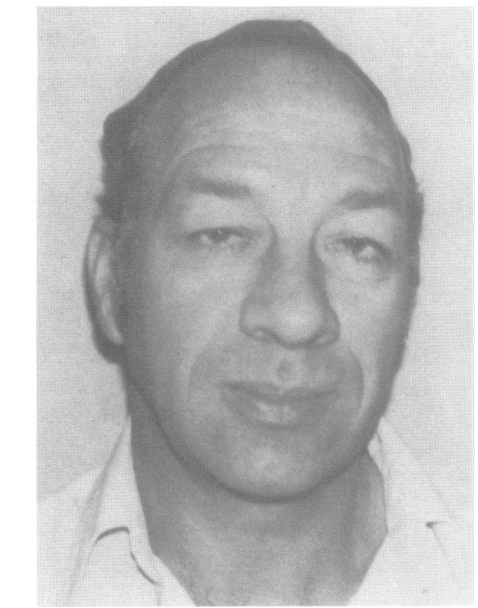

FIG 8 Father of proband (III.10) showing minimal expression of facial phenotype with fullness of the upper eyelids and slightly thickened lower lip.
(III.7), 48 years (III.11), and 12 years (IV.28) were 을 within normal limits. Radiographs of the proband's hands showed prominent tufts at the end of the distal phalanges (fig 9) but there was no evidence of periosteal thickening. It has not been possible to biopsy the skin in any of the affected subjects.

\section{Linkage analysis}

A wide variety of genetic markers expressed in blood were examined and the data obtained were tested for linkage with the disease locus (here designated $A F A$ : acromegaloid facial appearance). Lod scores were obtained by Côté's Mark III adaptation of Edwards's computer programme. ${ }^{1}$

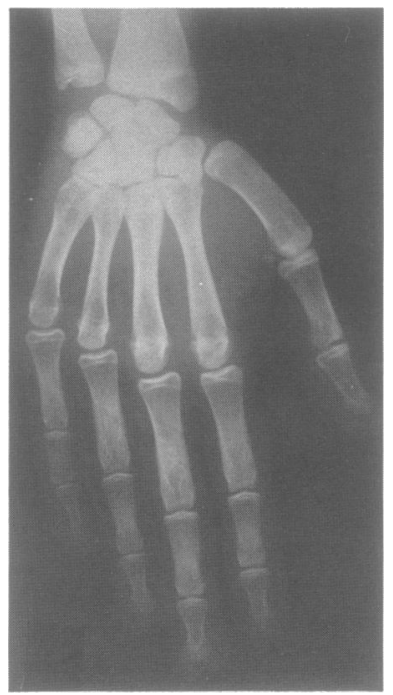

FIG 9 Radiograph of proband's hand showing distal phalangeal tufting. 
TABLE 1 Lod scores with marker loci.

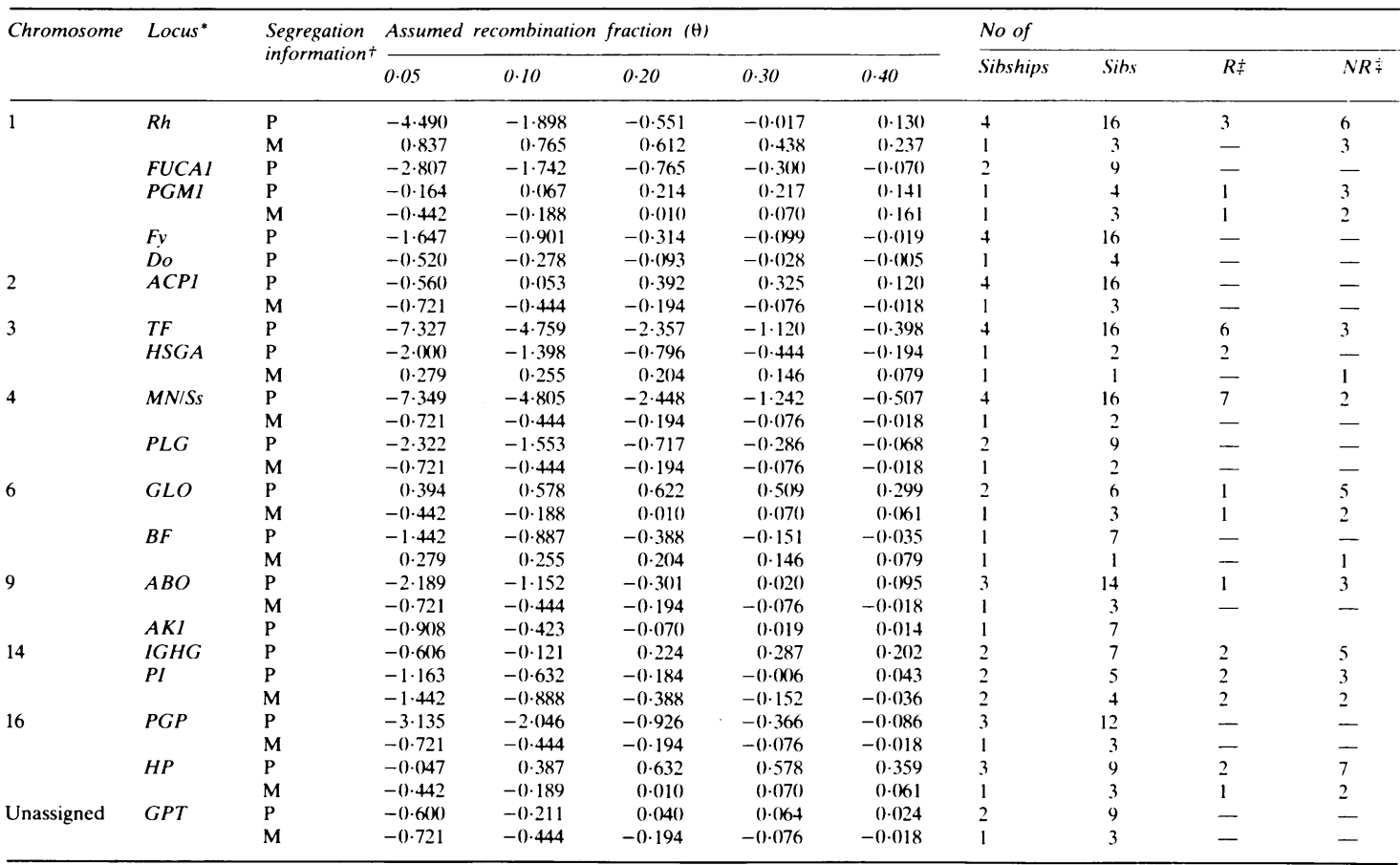

* Locus designations and chromosome assignments as defined by Shows et al. ${ }^{2}$

† P. paternal: M. maternal.

$\ddagger R$. recombinants; NR, non-recombinants.

The lod scores obtained from the linkage analysis of the genetic marker data are summarised in table 1 . Lod scores from male meioses were $<-2$ with $T F$ and $M N / S s$ at $\theta \leq 0 \cdot 20$, with $P G P$ at $\theta \leq 0 \cdot 10$, and with Rh, FUCA1, HSGA, PLG, and $A B O$ at $\theta$ $\leq 0.05$. The lod scores from the male segregation data for $F y, D o$, and $B F$ were somewhat negative at all values of $\theta$ tested, while the scores with $P G M 1$, $A C P 1, A K 1, I G H G, P I, H P$, and $G P T$ were slightly positive at larger values of $\theta$. The available recombinant (R):non-recombinant (NR) counts did not differ significantly from independence. The $A F A: G L O$ scores from males were positive at all values of $\theta$ tested.

\section{Discussion}

In this kindred, affected relatives span at least five generations and the phenotype segregates in a manner consistent with autosomal dominant inheritance. The most striking features of the syndrome are thickened lips (without a true double lip), overgrowth of the intraoral mucosa resulting in exaggerated rugae and frenula, and thickened upper eyelids leading to narrow palpebral fissures (blepharophimosis). The facial appearance and large doughy hands are reminiscent of acromegaly, and such acromegaloid-like facial changes have been described in a number of dominant conditions, for example, pachydermoperiostosis and the Ascher and multiple neuroma syndromes. However, there are sufficient differences in this family to justify its separate classification (table 2).

Pachydermoperiostosis is a syndrome characterised by progressively coarse facies, deep furrowed scalp (cutis verticus gyrata), clubbed fingers, and periosteal new bone formation. ${ }^{3}$ The condition is highly variable but clubbed fingers appear to be a constant feature and, together with radiographic evidence of periostosis, may be the only manifestation in milder cases. ${ }^{4-7}$ The phenotype of affected subjects in our family is consistent with partial expression of pachydermoperiostosis, but in this large kindred one would expect at least one affected member with full expression of the disorder. Of the 13 affected persons (five over the age of 35 years) examined by one of us (HEH), none had evidence of digital clubbing. Furthermore, finger clubbing is not reported in 12 other relatives for whom a descriptive history or photographs or both are 
TABLE 2 Comparison of clinical features.

\begin{tabular}{|c|c|c|c|c|}
\hline & Present family & Pachydermoperiostosis & Ascher syndrome & $M N S$ \\
\hline \multicolumn{5}{|l|}{ Head } \\
\hline Coarse facies ('acromegaloid') & ++ & ++ & + & ++ \\
\hline Furrowed skin & - & ++ & - & $?+$ \\
\hline Blepharochalasis & ++ & + & ++ & + \\
\hline Eye abnormality & - & - & - & $\begin{array}{l}\text { Thickened } \\
\text { corneal nerves }\end{array}$ \\
\hline Bulbous nose & ++ & + & - & $?+$ \\
\hline Prominent lips & $\begin{array}{l}++ \\
\text { (Lower) }\end{array}$ & + & $\begin{array}{l}++ \\
\text { (Upper) }\end{array}$ & ++ \\
\hline Increased mucosal folds & ++ & - & + & - \\
\hline Nodular tongue & - & - & - & + \\
\hline \multicolumn{5}{|l|}{ Extremitics } \\
\hline Soft tissue swelling & + & ++ & - & + \\
\hline Hyperextensible hand joints & + & - & - & + \\
\hline Clubbing & - & ++ & - & - \\
\hline Periosteal thickening & - & ++ & - & - \\
\hline Endocrine & - & - & Goitre & $\begin{array}{l}\text { Ca thyroid. } \\
\text { phaeochromocytoma }\end{array}$ \\
\hline
\end{tabular}

available. Swelling of the lips and mucosal folds are prominent presenting features in our family, but neither of these changes is diagnostic of pachydermoperiostosis, especially in the absence of other more typical signs.

Another condition included in the differential diagnosis is the Ascher syndrome. In the complete form of this syndrome, there is blepharochalasis, double lip, and non-toxic thyroid enlargement. ${ }^{89}$ Thickened intraoral mucosa has also been reported. However, in the Ascher syndrome the upper lip is more commonly affected and the swelling tends to be lobulated, discrete, and soft. ${ }^{10}$ " 11 In contrast, this family has lower lip involvement and the swelling is diffuse. In the Ascher syndrome, the upper eyelids first become enlarged and eventually wrinkle and droop. ${ }^{12} 13$ However, in our family the skin is thickened over the orbital margins and not in the lower part of the eyelid as is the case in the Ascher syndrome. Moreover, changes in the extremities are not reported in the Ascher syndrome.

There is a facial resemblance between members of our family and patients with the multiple neuroma syndrome (MNS) ${ }^{14}$ also known as multiple endocrine neoplasia type III or IIB. Persons with MNS can have a coarse face, prominent lips, and hyperextensible digital joints, but cardinal features for diagnosis include multiple neuromas, phaeochromocytoma, and medullary thyroid carcinoma. ${ }^{14-16}$ The phenotype in the family we describe is consis- tent with partial expression of MNS, but no subject

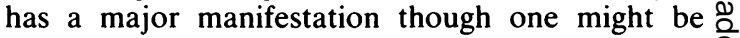
expected in a kindred with so many affected $\stackrel{\perp}{\perp}$ members. The seven living sibs in generation II are $\overrightarrow{\vec{P}}$ now in their 70s and none has a history suggestive of $\frac{0}{3}$ an endocrine problem or malignancy. Of the four dead sibs, one died in childbirth and three were reported to have had 'heart attacks' late in life.

In summary, despite a number of overlapping phenotypic features, the autosomal dominant syn- $\dot{\sigma}$ drome in this family appears distinct from pachydermoperiostosis and the Ascher and MNS $\delta$ syndromes. To the best of our knowledge it has not $₹$ been previously reported. While the $A F A$ gene 을 cannot be mapped to a specific location from the data obtained in this study, the lod scores and the R:NR counts with $R h$ and $P G M 1$ (chromosome 1), $G L O$ (chromosome 6), IGHG and $P I$ (chromosome $N$ 14), and $H P$ (chromosome 16) do not exclude loose $N$ linkage.

The authors thank Mrs Louise Carrière for her help in studying this family and Drs $\mathrm{J} \mathrm{K}$ Finegan and M W Thompson for their review of the manuscript. $\stackrel{\mathcal{D}}{?}$ We acknowledge the expert technical assistance of 0 L Komarnicki, E Leitchman, T Mansfield, $M$ Mendoza, and D Wills. This study was funded in part by the Medical Research Council of Canada (MT6112) and the Children's Hospital of Winnipeg Research Foundation Inc. 


\section{References}

1 Côté GB. Centromeric linkage in man. PhD thesis, University of Birmingham, 1975.

2 Shows TB, McAlpine PJ, Miller RL. The 1983 catalogue of mapped human genetic markers and report of the nomenclature committee. Human gene mapping 7 (1984). Seventh International Workshop on Human Gene Mapping. Birth Defects 1984;20:340-93.

3 Touraine A, Solente G, Golé L. Un syndrome ostéodermopathique: la pachydermie plicaturée avec pachypériostose des extrémités. La Presse Med 1935:43:1820-4.

4 Vogl A, Goldfischer S. Pachydermoperiostosis: primary or idiopathic hypertrophic osteoarthropathy. $\mathrm{Am} \mathrm{J} \mathrm{Med}$ 1962;33:166-87.

5 Rimoin DL. Pachydermoperiostosis (idiopathic clubbing and periostosis): genetic and physiologic considerations. $N$ Engl J Med 1965;272:923-31.

6 Hambrick GW, Carter DM. Pachydermoperiostosis: TouraineSolente-Golé syndrome. Arch Dermatol 1966;94:594-607.

7 Rollier R, Sebti A, Rollier M, Cherkaoui A, Devico V. A propos de trois cas de pachydermopériostose. J Med Lyon 1972;53:1148-62.

${ }^{8}$ Ascher KW. Blepharochalasis mit struma und doppellippe. Klin Monatsbl Augenheilkd 1920;65:86-97.

9 Findlay GH. Idiopathic enlargements of the lips: cheilitis granulomatosa. Ascher's syndrome and double lip. $\mathrm{Br} J$ Dermatol 1954;66:129-38.

10 Schimpf A. Das Ascher-syndrom. Dermatol Wochenschr 1955:132:1077-86.

1 Papanayotou PH, Hatziotis JC. Ascher's syndrome: report of a case. Oral Surg 1973:35:467-71.

12 Barnett ML. Bosshardt LL. Morgan AF. Double lip and double lip with blepharochalasis (Ascher's syndrome). Oral Surg 1972:34:727-33.

13 Goodman RM, Gorlin RJ. Atlas of the face in genetic disorders. St Louis: Mosby, 1977.

14 Williams ED, Pollock DJ. Multiple mucosal neuromata with endocrine tumours: a syndrome allied to von Recklinghausen's disease. J Pathol Bacteriol 1966;91:71-80.

15 Gorlin RJ, Sedano HO, Vickers RA, Cervenka J. Multiple mucosal neuromas, pheochromocytoma and medullary carcinoma of the thyroid-a syndrome. Cancer 1968:22:293-9.

16 Schimke RN, Hartmann WH, Prout TE, Rimoin DL. Syndrome of bilateral pheochromocytoma, medullary thyroid carcinoma and multiple neuromas. $N$ Engl J Med 1968;279:1-7.

Correspondence and requests for reprints to Dr H E Hughes, Department of Genetics, The Hospital for Sick Children, 555 University Avenue, Toronto, Ontario, Canada M5G 1 X8. 